\title{
Critical role of $\mathrm{CDK} 11^{\mathrm{p} 58}$ in human breast cancer growth and angiogenesis
}

\author{
Yayun $\mathrm{Chi}^{{ }^{\dagger \dagger}}$, Sheng Huang ${ }^{1 \dagger}$, Haojie Peng ${ }^{2}$, Mengying Liu ${ }^{1}$, Jun Zhao ${ }^{2}$, Zhiming Shao ${ }^{1}$ and Jiong $\mathrm{Wu}^{1 *}$
}

\begin{abstract}
Background: A capillary network is needed in cancer growth and metastasis. Induction of angiogenesis represents one of the major hallmarks of cancer. CDK11 ${ }^{\mathrm{p} 58}$, a Ser/Thr kinase that belongs to the Cell Division Cycle 2-like 1 (CDC2L1) subfamily is associated with cell cycle progression, tumorigenesis, sister chromatid cohesion and apoptotic signaling. However, its role in breast cancer proliferation and angiogenesis remains unclear.

Methods: Tumorigenicity assays and blood vessel assessment in athymic mice were used to assess the function of CDK1 ${ }^{p 58}$ in tumor proliferation and angiogenesis. CCK-8 assay was used to detect breast cancer cell growth. Immunohistochemistry was used to detect the expression of vascular endothelial growth factor (VEGF), CD31 and CD34 in CDK11 positive patient breast cancer tissues. Dual-Luciferase array was used to analyze the function of CDK11 158 in the regulation of VEGF promoter activity. Western blot was used to detect related protein expression levels.
\end{abstract}

Results: $\mathrm{CDK} 11^{\mathrm{p} 58}$ inhibited breast cancer growth and angiogenesis in breast cancer cells and in nude mice transplanted with tumors. Immunohistochemistry confirmed that CDK1 $1^{\mathrm{p} 58}$ was negatively associated with angiogenesis-related proteins such as VEGF, CD31 and CD34 in breast cancer patients. Real-time PCR and dual-luciferase assay showed CDK $11^{\mathrm{p} 58}$ inhibited the mRNA levels of VEGF and the promoter activity of VEGF. As CDK $11^{\mathrm{p} 58}$ is a Ser/Thr kinase, the kinase-dead mutant failed to inhibit VEGF mRNA and promoter activity. Western blot analysis showed the same pattern of related protein expression. The data suggested angiogenesis inhibition was dependent on CDK1 $1^{\mathrm{p} 58}$ kinase activity.

Conclusion: This study indicates that CDK $11^{\mathrm{p} 58}$ inhibits the growth and angiogenesis of breast cancer dependent on its kinase activity.

Keywords: CDK1 $11^{\mathrm{p} 58}$, Angiogenesis, Kinase activity, VEGF

\section{Background}

Blood vessels deliver oxygen and nutrients to every part of the body, but also nourish diseases such as cancer [1]. A capillary network from the surrounding host tissue is needed both in cancer proliferation and in cancer metastasis [2]. Angiogenesis is a physiological multi-step process that includes endothelial cell growth and movement [3]. Induction of angiogenesis represents one of the major hallmarks of cancer [4], and plays important roles in wound healing, endothelial cell-mediated degradation of the extracellular matrix, and the transition of benign tissues into solid tumors [5]. Therefore, there is a great and urgent need to study the regulation and

\footnotetext{
* Correspondence: wujiong1122@vip.sina.com

'Equal contributors

${ }^{1}$ Department of Breast Surgery, Breast Cancer Institute, Fudan University

Shanghai Cancer Center, Shanghai 200032, China

Full list of author information is available at the end of the article
}

elucidate the mechanisms of cancer angiogenesis. Vascular endothelial growth factor (VEGF) is a predominant activator of endothelial cell functions such as new blood vessel formation (angiogenesis) during development [6]. Through a VEGF-induced signaling pathway, VEGF plays a vital role in the proliferation, migration, and invasion of vascular endothelial cells. In addition, other growth factors such as integrins, matrix metalloproteinases (MMPs) and growth factor receptors (GFRs) also stimulate angiogenesis [1]. As previously reported, VEGF is an important angiogenic factor in human breast cancer [7]. Microvessel density in areas of intense neovascularization in invasive breast carcinoma is an independent and highly significant prognostic indicator for overall and relapse-free survival in patients with early-stage breast carcinoma [8].

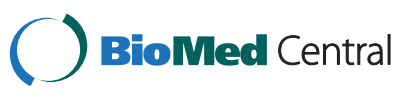

(c) 2015 Chi et al. Open Access This article is distributed under the terms of the Creative Commons Attribution 4.0 International License (http://creativecommons.org/licenses/by/4.0/), which permits unrestricted use, distribution, and reproduction in any medium, provided you give appropriate credit to the original author(s) and the source, provide a link to the Creative Commons license, and indicate if changes were made. The Creative Commons Public Domain Dedication waiver (http://creativecommons.org/publicdomain/zero/1.0/) applies to the data made available in this article, unless otherwise stated. 
CDK $11^{\mathrm{p} 58}$, a $\mathrm{G} 2 / \mathrm{M}$ phase protein associated with cell cycle progression and tumorigenesis [9], is a centrosomeassociated mitotic kinase involved in centrosome maturation and bipolar spindle formation and is required for centriole duplication and Plk4 recruitment to mitotic centrosomes $[10,11]$. Previously, we found that CDK11 ${ }^{\mathrm{p} 58}$ inhibited the proliferation of prostate cancer and was involved in regulation of androgen and estrogen signaling [12-14]. In addition, our previous study demonstrated that $\mathrm{CDK} 11^{\mathrm{p} 58}$ inhibited ER $\alpha$-positive breast cancer invasion by targeting integrin $\beta 3$ via the repression of ER $\alpha$ signaling [15] and also we found breast cancers transfected with $\mathrm{CDK} 11^{\mathrm{p} 58}$ grew slowly compared with the control cell lines, so we speculated that $\mathrm{CDK} 11^{\mathrm{p} 58}$ might inhibit the growth of breast cancer.

In the current study, we evaluated the direct antitumor and anti-angiogenic effects of CDK $11^{\mathrm{p} 58}$ in breast cancer. An in vivo model of human breast cancer cell xenografts in nude mice was used to assess the effects and mechanism of $\mathrm{CDK} 11^{\mathrm{p} 58}$ on tumor growth and angiogenesis. We sought to determine the potential role of $\mathrm{CDK} 11^{\mathrm{p} 58}$ in breast cancer growth and angiogenesis as well as the underlying mechanisms.

\section{Methods}

\section{Samples}

A tissue array including 32 breast cancer patient cancerous tissues were obtained from the tissue bank of Fudan University Shanghai Cancer Center in 2010. This study was approved by the Ethical Committee of our Cancer Center and written informed consent was obtained from each patient.

\section{Materials}

Fetal bovine serum (FBS), Dulbecco's modified Eagle medium (DMEM), 1640 and expression vector pcDNA3.0 were purchased from Invitrogen (Invitrogen, USA). Mouse and rabbit secondary antibodies for immunohistochemistry (IHC) were purchased from Cell Signaling (CST, USA). Anti-HA and anti-CDK11 polyclonal antibodies were purchased from Santa Cruz Biotechnology (Dallas, Texas, USA). VEGF, CD31, CD34, integrin $\beta 3, \mathrm{mmp} 3$ and mmp9 were all purchased from Epitomics Company (Abcam, Cambridge, MA USA). Anti-GAPDH antibodies was purchased from Proteintech (Beijing, China). A dual luciferase reporter assay system was purchased from Promega (Beijing, China).

\section{Cell culture and cell transfections}

293 T, MCF7, MDA-MB-231 and T47D cell lines were obtained from our laboratory cell bank. 293 T, MCF-7 and T47D cells were grown using DMEM supplemented with $10 \%$ FBS, $100 \mu \mathrm{g} / \mathrm{ml}$ penicillin, and $100 \mu \mathrm{g} / \mathrm{ml}$ streptomycin (Cat. 10378-016, Invitrogen) at $37{ }^{\circ} \mathrm{C}$ and
$5 \% \mathrm{CO}_{2}$. MDA-MB-231 cells were cultured using F15 supplemented with $10 \% \mathrm{FBS}, 100 \mu \mathrm{g} / \mathrm{ml}$ penicillin and $100 \mu \mathrm{g} / \mathrm{ml}$ streptomycin at $37{ }^{\circ} \mathrm{C}$ and $5 \% \mathrm{CO}_{2}$. Transient transfection for luciferase assays was performed using 96-well plates $\left(1 \times 10^{4}\right.$ cells per well) with $200 \mathrm{ng}$ of total plasmids and Lipofectamine 2000 reagent (Cat.11668-019, Invitrogen) according to the manufacturer's instructions.

\section{Stable expression of $\mathrm{CDK} 11^{\mathrm{p} 58}$ with retroviral vector} Human CDK $11^{\mathrm{p} 58}$ was cloned into pBabe-puro vector for ectopic expression of CDK11 ${ }^{\mathrm{p} 58}$. MDA-MB231 and T47D cells were infected with pBabe-puro vector control or $\mathrm{CDK} 11^{\mathrm{p} 58}$-overexpression virus and selected by Puromycin. The expression levels of $\mathrm{CDK} 11^{\mathrm{p} 58}$ in MDAMB231 and T47D were confirmed by Western blot assay.

\section{Tumorigenicity assays and blood vessel assessment in athymic mice}

Female athymic BALB/c nu/nu mice, 4-6 weeks old, were obtained from the Shanghai Institute of Materia Medica, Chinese Academy of Sciences. All studies on mice were conducted in accordance with the National Institute of Health (NIH) 'Guide for the Care and Use of Laboratory Animals'. The study protocol was approved by the Shanghai Medical Experimental Animal Care Committee. Animals were divided into four groups: MDA-MB-231/vector and MDA-MB-231/CDK11 ${ }^{\mathrm{p} 58}$, $\mathrm{T} 47 \mathrm{D} /$ vector and $\mathrm{T} 47 \mathrm{D} / \mathrm{CDK} 11^{\mathrm{p} 58}$. Each group contained 16 mice. Cells (MDA-MB-231, $1.5 \times 10^{6}$ and T47D, $1 \times 10^{7}$ ) were injected into the No.4 pairs of mammary fat pad of mice. Animals were monitored every 2 days for tumor growth and general health. Tumor sizes were measured with caliper and calculated by the formula $\mathrm{V}=(\mathrm{W})^{2} \mathrm{xL} / 2$. Animals were sacrificed and autopsied at 6 weeks after cell inoculation. To confirm the expression of the indicated proteins, sections were cut at $50 \mu \mathrm{m}$ intervals and stained with hematoxylin and eosin $(\mathrm{H} \& \mathrm{E})$ and by $\mathrm{IHC}$.

For blood vessels imaging preparation, the image contrast agent, barium sulfate suspended in glycerol (50 \% water solution; a concentration of $0.5 \mathrm{mg} / \mathrm{mL}$ ), was injected into the deeply anesthetized mouse ascending aorta. Then the tumors were excised and fixed by $4 \%$ paraformaldehyde followed by graded ethanol. The microangiography for blood vessels was performed at the Beamline BL13W1, the biomedical application station of the Shanghai Synchrotron Radiation Facility (SSRF) in China. The maximum light size of the beam was $45 \mathrm{~mm}$ (horizontal) $\times 5 \mathrm{~mm}$ (vertical) at the object position at $16 \mathrm{keV}$. Projections of tumor samples in nude mice were then recorded using SSRF. The slice images were reconstructed using the filtered back projection (FBP) algorithm. The vessels of tumor were segmented from these slice images after reducing noise by using Gauss 
smoothing filter in Matlab. Moreover, thinning algorithm was applied to extract the skeletons of vessels in order to evaluate the status of tumor. After these image preprocessing, micro vessel density (MVD), number of vessel branches and number of vessel nodes were computed in each tumor sample.

\section{Cell counting kit-8 assay}

Stable transfected cells were seeded in a 96-well plate at $5 \times 10^{3}$ cells per well and then cultured for 4 days. A volume of $10 \mu \mathrm{l}$ of CCK-8 (Cell Counting Kit-8, C0038, Beyotime, Shanghai, China) solution was added to each well of the plate and incubated at $37{ }^{\circ} \mathrm{C}$ for $4 \mathrm{~h}$. The absorbance at $450 \mathrm{~nm}$ was measured to represent the cell viability.

\section{Immunohistochemistry}

Expression levels of CDK11 (Sc-928, Santa Cruz, USA), VEGF (ab46154, Abcam, USA), CD31 (GM082329, GeneTech, Shanghai, China), and CD34 (GM716529, GeneTech) in postoperative paraffin-embedded tumor specimens from breast cancer patients and mice tumor tissues were detected with IHC. The concentrations of antibodies used are as follows: CDK11, 1:100; VEGF, 1:100; CD31, 1:50; and CD34, 1:50. The Envision and diaminobenzidine (DAB) Color Kit was purchased from Gene Tech Company Limited (Shanghai, China). The staining procedures strictly followed the supplier's recommendation. The staining index (SI, range 0-9) was considered as the product of the intensity score $(0$, no staining; $1+$, faint/equivocal; $2+$, moderate; $3+$, strong) and the distribution score ( 0 , no staining; $1+$, staining of $<10 \%$ of cells; $2+$, between $10 \%$ and $50 \%$ of cells; and $3+,>50 \%$ of cells). For CDK11 protein in this study, a moderate/strong staining $(\mathrm{SI}=3-9)$ was defined as positive or high staining, and a weak or negative staining $(\mathrm{SI}=0-2)$ was defined as negative or low staining.

\section{In vitro angiogenesis model}

Human Umbilical Vein Endothelial Cells (HUVEC), which were obtained from our laboratory cell bank were suspended in culture medium from stable cell lines and then plated onto a thin layer $(300 \mathrm{ml})$ of basement membrane matrix (Matrigel; BD Biosciences) in 24-well plates at $1 \times 10^{4}$ cells/well. After $12 \mathrm{~h}$, the medium was removed, cells were fixed, and images of cells were obtained with a light microscope (Laica) at $\times 20$ magnification. Quantification of the tubular structures (anastomosing tubules) was performed by counting the number of complete circles produced by interlinking tubular HUVECs [16].

\section{Dual luciferase reporter assays}

293 T, T47D and MCF-7 cells were cotransfected with a VEGF promoter luciferase reporter construct (100 ng) [17], a control Renilla luciferase plasmid (pRL) (1 ng), CDK $11^{\mathrm{p} 58}$ or other mutants. Total plasmid DNA was adjusted to $300 \mathrm{ng}$ with an empty pcDNA vector. At $48 \mathrm{~h}$ post-transfection, a dual luciferase reporter gene assay (Promega) was performed following the instructions using a SynergyHT Multi-Mode Microplate Reader (BioTek, USA).

\section{Western blot analysis}

Cell pellets were lysed, protein extracts were quantitated, loaded onto a $10 \%$ sodium dodecyl sulfatepolyacrylamide gel, electrophoresed, and transferred to a nitrocellulose membrane. The membrane was incubated with primary antibody, washed, and incubated with horseradish peroxidase (HRP)-conjugated secondary antibody (Cell Signaling). Detection was performed usig chemiluminescent Western detection kit. GAPDH was using as a loading control. The quantification of immunoblotting was done by the Photoshop Software.

\section{Statistical analysis}

Results are either representative or are the mean of at least three independent experiments performed in triplicate. Statistical analysis was performed using ANOVA test and Student's t-test for unpaired data (Prism, GraphPad). Chisquared test analyses were performed using SPSS (version 19.0; SPSS Company). $P<0.05$ was considered statistically significant.

\section{Results}

CDK $11^{\mathrm{p} 58}$ inhibits the growth of breast cancer

To evaluate the role of $\mathrm{CDK} 11^{\mathrm{p} 58}$ in breast cancer, we first constructed $\mathrm{CDK} 11^{\mathrm{p} 58}$ stable breast cancer cell lines in ER negative MDA-MB231 and ER positive T47D. Western blot assay showed that CDK $11^{\mathrm{p} 58}$ was more highly expressed in the two stable cell lines than the control pBABE group and wild type group (Fig. 1a). By Cell Counting Kit-8 assay, we found that CDK $11^{\mathrm{p} 58}$ inhibited breast cancer cell gowth compared with the pBABE control both in MDA-MB231 and T47D cells (Fig. 1b). Colony formation assay was used to examine the effect of $\mathrm{CDK} 11^{\mathrm{p} 58}$ in tumorigenesis and also demonstrated that $\mathrm{CDK} 11^{\mathrm{p} 58}$ inhibited the growth and tumorigenesis of breast cancer cells (Fig. 1c, Additional file 1: Figure S1A).

Then we further investigated the role of CDK $11^{\mathrm{p} 58}$ in tumor growth by using an in vivo orthotopic xenograft tumor model in athymic mice. MDA-MB-231/ vector/CDK $11^{\mathrm{p} 58}$ or $\mathrm{T} 47 \mathrm{D} /$ vector/CDK $11^{\mathrm{p} 58}$ cells were injected into the No. 4 mammary fat pad of athymic mice. At 6 weeks, we measured the size of tumors and monitored tumor cell growth. CDK $11^{\mathrm{p} 58}$ inhibited in vivo tumor growth significantly (Fig. 1d, Additional file 1: Figure S1B). 


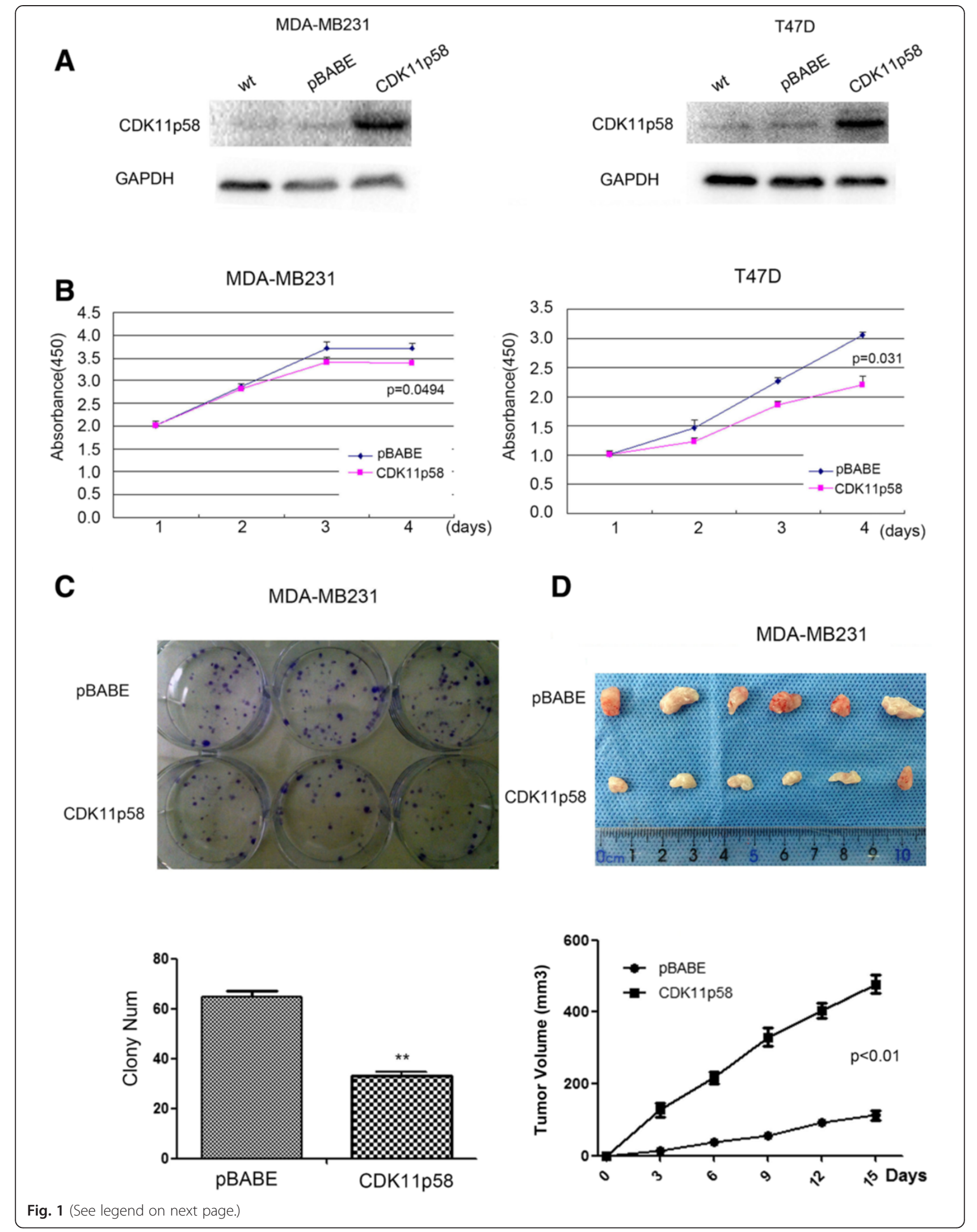


(See figure on previous page.)

Fig. 1 CDK $11^{\mathrm{p} 58}$ inhibits the proliferation of breast cancer. (a) CDK1 $11^{\mathrm{p} 58}$ expression was detected by western blot assay in a CDK $11^{\mathrm{p} 58}$ stable cell line in MDA-MB231 and T47D cells. (b) CCK-8 proliferation analysis of CDK1 $1^{\text {p58 }}$ stable transfected breast cancer cells MDA-MB231 and T47D compared with controls. (c) Colony formation of human breast cancer cells stably transfected with CDK11 ${ }^{\text {p58 }}$ or pcDNA3.0. ${ }^{* *} P<0.01$. (d) Tumorigenesis after injection of MDA-MB231 cells stably expressing CDK1 ${ }^{\mathrm{p58}}$ or control pBABE. Growth curve with CDK1 $11^{\mathrm{p} 58}$ stable expression and controls was also shown

\section{CDK $11^{\mathrm{p} 58}$ inhibits the angiogenesis of breast cancer} In the nude mice tumor model, we detected the cancer tissue expressions of CDK11 ${ }^{\mathrm{p} 58}$, VEGF, CD31 and CD34 by IHC. CDK $11^{\mathrm{p} 58}$ expression was significantly high in the stable expression group. CDK11 ${ }^{\mathrm{p} 58}$ inhibited the expression of VEGF, CD31 and CD34 in breast tumors compared with the control group (Fig. 2a). Because VEGF is involved in promoting breast cancer angiogenesis, pseudocapillary formation in matrigel with HUVECs was first measured using the conditioned media of the two series of breast cancer cells. CDK $11^{\mathrm{p} 58}$ stable expression and control breast cancer cells were cultured for 48 hours, then the conditioned medias were obtained. When plated in a thin layer of matrigel and stimulated with the conditioned medias, HUVECs were organized in a network of pseudocapillary tubes that invaded the gel (Fig. 2b). CDK $11^{\mathrm{p} 58}$ treatment reduced the number of pseudocapillaries in terms of completed circles in MDA-MB-231 and T47D

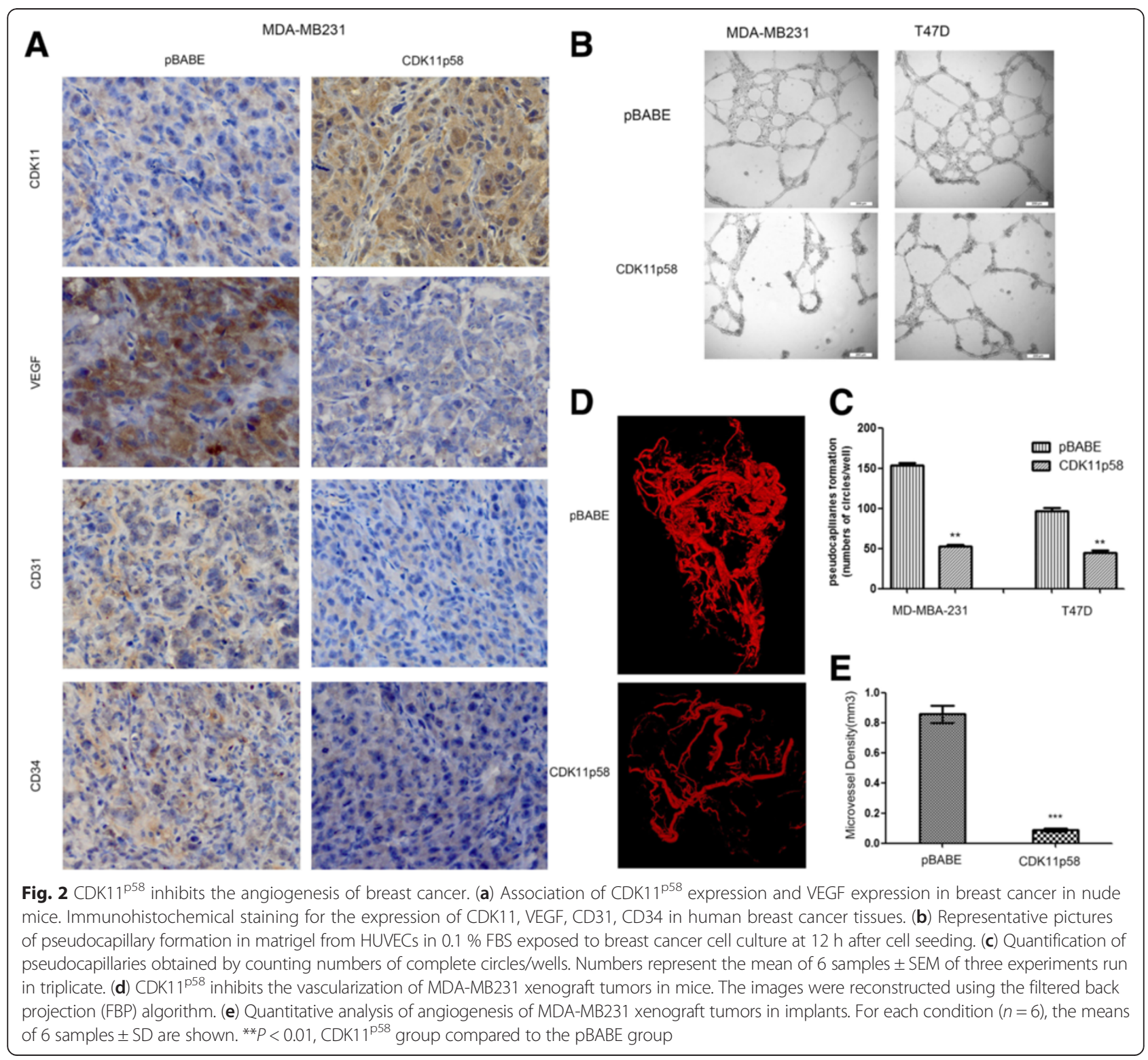


(Fig. 2c for quantification). These data suggest that CDK $11^{\mathrm{p} 58}$ inhibited pseudocapillary formation in both MDA-MB231 and T47D.

Blood vessels of tumors were then examined. As shown in Fig. 2d and e, the density of blood vessels in MDAMB231 tumors was attenuated significantly in tumors expressing high levels of $\mathrm{CDK} 11^{\mathrm{p} 58}$ relative to control groups (Table 1). Both tumor size and the MVD (micro-vascular density) were inhibited by $\mathrm{CDK} 11^{\mathrm{p} 58}$ in the MDA-MB231 group (Fig. 2d, e) and T47D groups (Additional file 1: Figure S1C). In addition, the vessel branches and nodes in the tumors were attenuated by $\mathrm{CDK} 11^{\mathrm{p} 58}$. These data suggest that $\mathrm{CDK} 11^{\mathrm{p} 58}$ inhibited breast tumor angiogenesis and proliferation in vivo.

\section{CDK $11^{\mathrm{p} 58}$ is associated with decreased angiogenesis in breast cancer patients}

To determine further whether $\mathrm{CDK} 11^{\mathrm{p} 58}$ was involved in the regulation of angiogenesis in breast cancer, 32 breast cancer patient tumor tissues were used to examine the expression of $\mathrm{CDK} 11^{\mathrm{p} 58}$ and angiogenesis related factors. VEGF, CD31, CD34 and CDK11p58 were examined by tissue array. CDK11 ${ }^{\mathrm{p} 58}$ was expressed both in the nucleus and cell plasma. VEGF was expressed mainly in plasma. CD31 and CD34 were expressed specifically in vascular endothelial cells (Fig. 3). By IHC, we also observed high CDK11 expression in 18 cases and low expression in 14 cases. In the same patients' tissues, high VEGF expression was observed in 15 cases and low expression was observed in 15 cases. The expression pattern of CDK11 was opposite to that of VEGF, CD31 and CD34 staining. The value of Chi-squared test for the correlation between CDK11 and VEGF was 10.041 and the $P$ value was less than 0.01 (Table 2). The clinical data supported the negative association of $\mathrm{CDK} 11^{\mathrm{p} 58}$ with VEGF and demonstrated CDK $11^{\mathrm{p} 58}$ inhibited angiogenesis in breast cancer.

\section{CDK $11^{\mathrm{p} 58}$ inhibits angiogenesis by inhibition of the VEGF signaling pathway}

To examine the regulation of VEGF by CDK11 ${ }^{\mathrm{p} 58}$, VEGF mRNA was detected by qRT-PCR. VEGF mRNA was inhibited by $\mathrm{CDK} 11^{\mathrm{p} 58}$ both in MDA-MB231 and in T47D (Fig. 4a). Promoter activity of VEGF assessed by

Table 1 Detail information of vessels in tumors

\begin{tabular}{lllllll}
\hline & Branches Nodes & $\begin{array}{l}\text { Size } \\
\left(\mathrm{mm}^{3}\right)\end{array}$ & MVD & $\begin{array}{l}\text { Average } \\
\text { OD (um) }\end{array}$ & $\begin{array}{l}\text { Max } \\
\text { OD (um) }\end{array}$ \\
\hline T47D pBabe & 18381 & 8000 & 1.5194 & 0.1465 & 17.6 & 138.22 \\
T47D CDK11p58 & 7418 & 2943 & 0.4365 & 0.0984 & 13.43 & 73.01 \\
231 pBabe & 23560 & 10341 & 1.4792 & 0.891 & 17.71 & 123.31 \\
231 CDK11p58 & 10166 & 3960 & 0.8135 & 0.0927 & 15.09 & 98.07 \\
\hline
\end{tabular}

OD: Outside Diameter, MVD: Micro-vessel Density, Size: Tumor sample size, Branches: vessel branches, Nodes: vessel nodes

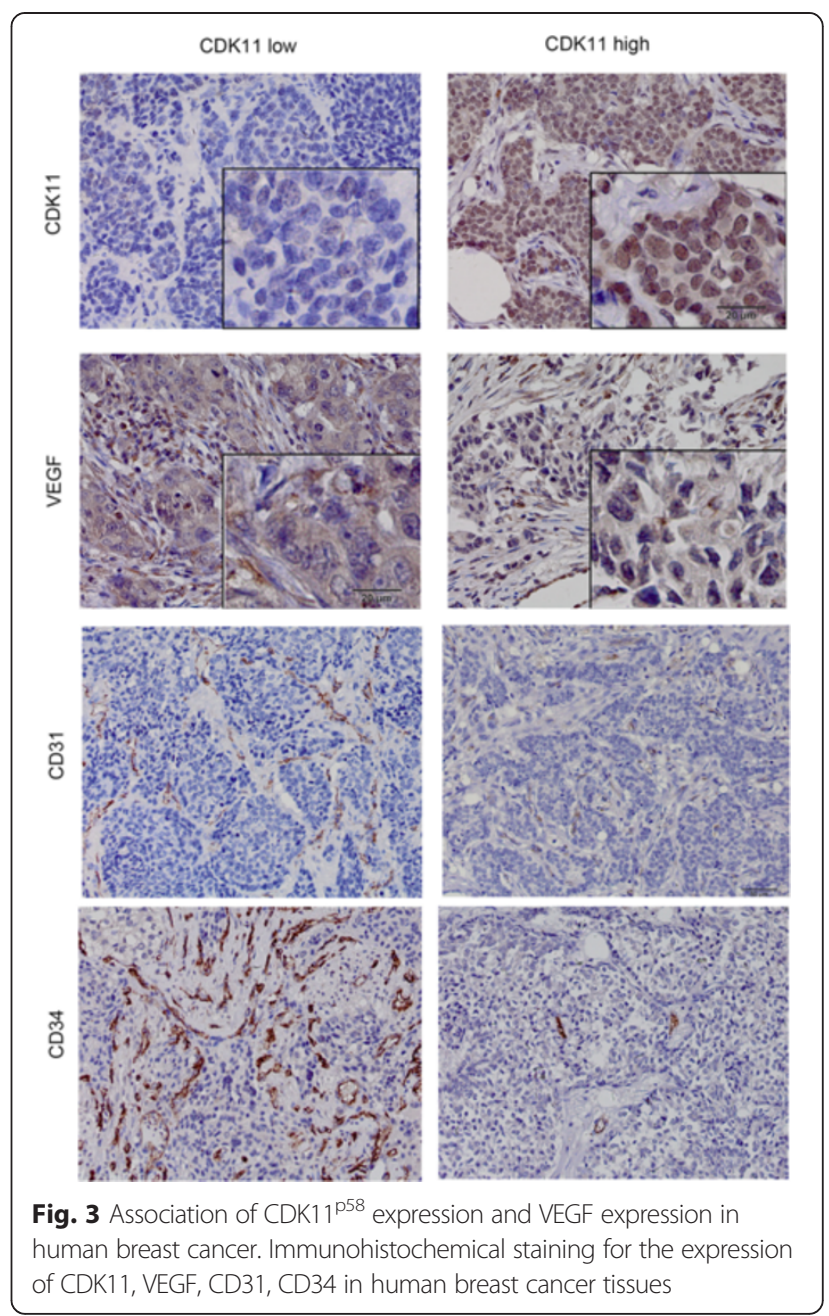

Dual luciferase assay in $293 \mathrm{~T}$ demonstrated that CDK $11^{\mathrm{p} 58}$ decreased the promoter activity of VEGF compared with the control in a dose dependent manner (Fig. 4b). In addition, CDK11 ${ }^{\mathrm{p} 58}$ inhibited the protein expression of VEGF, CD31, and other angiogenesis-related protein integrin $\beta 3$ (ITGB3) (Fig. 4c, the normalized quantification of immunoblotting data was shown in the Additional file 1: Figure S2A). CDK $11^{\mathrm{p} 58}$ is a Ser/Thr kinase and whether inhibition was dependent on its kinase activity was then examined. T370A and D224N are CDK11 ${ }^{\mathrm{p} 58}$ kinase dead mutants whereas T370D is a kinase-activated mutant as previously reported $[12,18]$. T370D inhibited the activity similar to the wild type.

Table 2 Correlation of CDK $11^{\mathrm{p} 58}$ and VEGF levels in breast cancer patients

\begin{tabular}{llllll}
\hline & $\mathrm{n}$ & \multicolumn{2}{l}{ VEGF expression } & $x^{2}$ & $p$ \\
\cline { 3 - 4 } & & Positive (\%) & Negative (\%) & & \\
\hline CDK11 positive & 18 & $4(12.5 \%)$ & $14(43.7 \%)$ & 10.041 & 0.004 \\
CDK11 negative & 14 & $11(34.4 \%)$ & $3(9.4 \%)$ & & \\
\hline
\end{tabular}




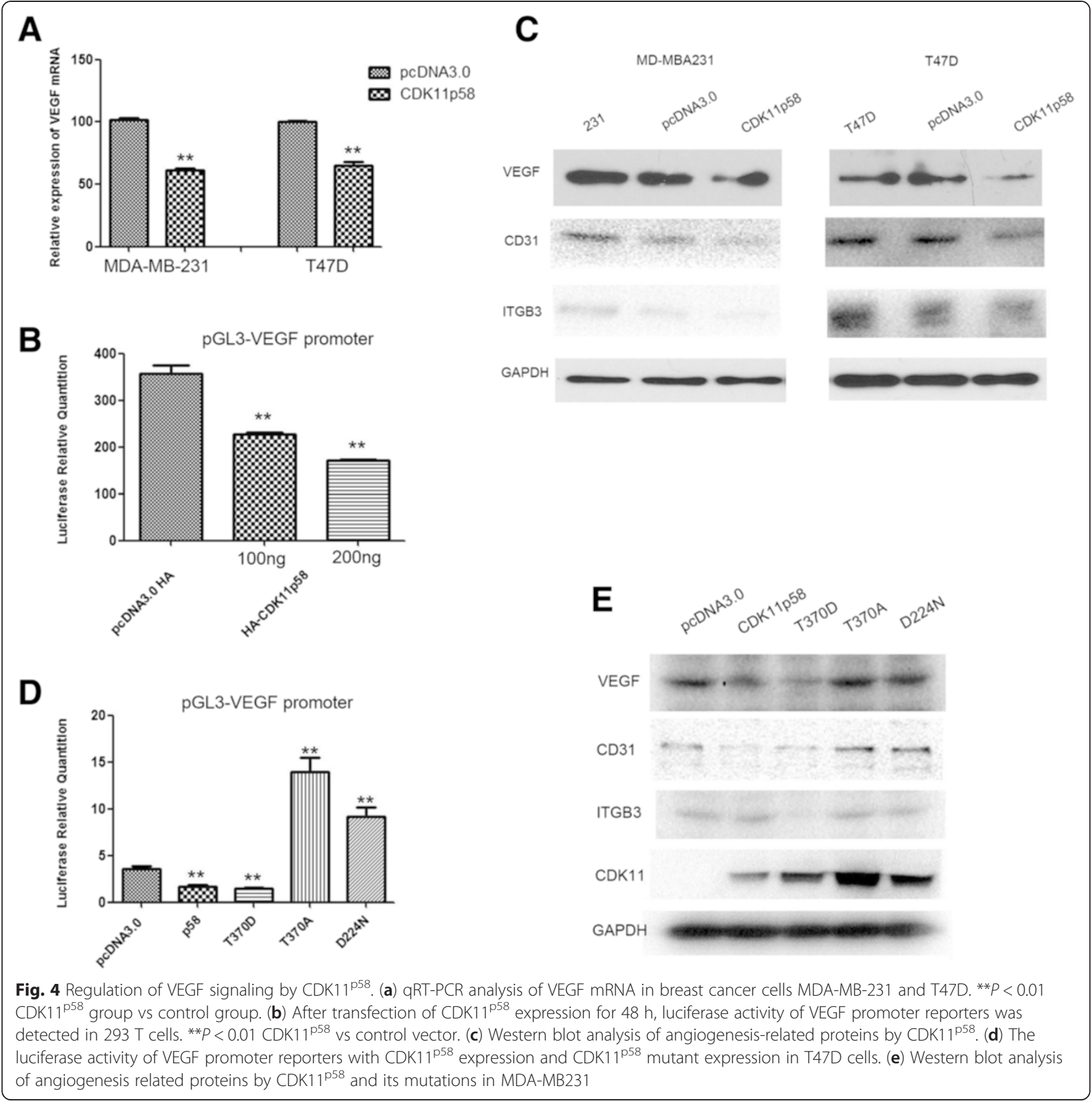

However, T370A and D224N lost the inhibitory ability but promoted the activity of the VEGF promoter (Fig. 4d). These data suggest that $\mathrm{CDK} 11^{\mathrm{p} 58}$ inhibited the promoter activity of VEGF in a kinase dependent manner. Western blotting also showed that CDK11 ${ }^{\mathrm{p} 58}$ inhibited the expression of VEGF, CD31 and integrin $\beta 3$ proteins in a kinase dependent manner in MDAMB231 cells (Fig. 4e, the normalized quantification of immunoblotting data was shown in the Additional file 1: Figure S2B). Taken together, these data suggest that CDK $11^{\mathrm{p} 58}$ inhibited angiogenesis through VEGF signaling in a kinase dependent way.

\section{Discussion}

In this study, we focused on the critical role of CDK $11^{\mathrm{p} 58}$ in breast cancer growth and angiogenesis, especially the regulation of VEGF by CDK $11^{\mathrm{p} 58}$ and the dependence on its kinase activity. First, we determined that $\mathrm{CDK} 11^{\mathrm{p} 58}$ inhibited the growth and formation of pseudocapillaries in breast cancer cells. Using a nude mouse model, CDK11p58 inhibited the growth and density of microvessels of the transplanted tumor. Second, by mice tumor tissues, we used IHC to determine a negative association of the expression of VEGF, CD31, and CD34 as well as MVD status with CDK11 expression. Similar results were 
observed in human breast cancer tissues. Then, we detected the regulation of VEGF by CDK $11^{\mathrm{p} 58}$ both in $293 \mathrm{~T}$ cells and breast cancer cells. CDK11 ${ }^{\mathrm{p} 58}$ inhibited the promoter activity of VEGF regulation at the transcriptional level and constantly inhibited angiogenesis-related protein expression in a kinase dependent manner.

Breast cancer is the most common female cancer and among the most frequent causes of cancer mortality in women worldwide $[19,20]$. Cancer can spread through tissues, the lymph system and the blood [21]. Breast cancer is prone to travel through the blood vessels to other parts of the body, mainly to the brain, bone and lung [22-24]. Angiogenesis is a critical process in tumor growth and metastasis [25]. VEGF family members are involved in the regulation of angiogenesis. VEGF is the main component of this family and stimulates angiogenesis in health and disease by signaling through VEGF receptor-2 $[3,26]$. Thus far, the VEGF-neutralizing antibody bevacizumab (Avastin) is used for metastatic colorectal, metastatic breast cancer and other metastatic cancers [25].

CDK $11^{\mathrm{p} 58}$ is involved in a variety of important regulatory pathways in eukaryotic cells, including cell cycle control, apoptosis, neuronal physiology, differentiation and autophagy [10, 27-31]. It is a Ser/Thr kinase and most of its functions are dependent on its kinase activity [32]. In our previous study, we found that $\mathrm{CDK} 11^{\mathrm{p} 58}$ repressed ERa transcription activity by promoting its ubiquitin-proteasome degradation in breast cancer [13].

In this study, we found that $\mathrm{CDK} 11^{\mathrm{p} 58}$ inhibited the growth and angiogenesis not only in breast cancer cells but also in a nude mouse breast tumor model. This revealed that $\mathrm{CDK} 11^{\mathrm{p} 58}$ might act as a tumor suppressor in breast cancer.

In the nude mouse cancer model and in the breast cancer patient samples assessed by IHC, we also found that $\mathrm{CDK}_{11}{ }^{\mathrm{p} 58}$ expression was negatively associated with angiogenesis related proteins VEGF, CD31 and CD34. Similar results were obtained in breast cancer cells. These data suggest that CDK11 ${ }^{\mathrm{p} 58}$ might inhibit tumor proliferation and progression by an influence on angiogenesis.

As VEGF predominately regulates angiogenesis and several studies reported that targeting VEGF gene could inhibit the proliferation and induce the apoptosis of human breast cancer cells and in mice models [33-35], we speculated that $\mathrm{CDK} 11^{\mathrm{p} 58}$ might inhibit angiogenesis through the regulation of VEGF. To confirm further the roles of CDK $11^{\mathrm{p} 58}$ and VEGF, the mRNA levels of VEGF were examined at different levels of CDK11 ${ }^{\mathrm{p} 58}$. We found that $\mathrm{CDK} 11^{\mathrm{p} 58}$ inhibited VEGF mRNA and promoter activity of VEGF. These results indicated that $\mathrm{CDK} 11^{\mathrm{p} 58}$ inhibited the angiogenesis of breast cancer by inhibiting the promoter activity of VEGF in a dose dependent manner. Based on our previous study, $\mathrm{CDK} 11^{\mathrm{p} 58}$ could also induce the apoptosis of cancer cells through blocking the cells into the G2/M cell phase. So the mechanism involved in the growth and angiogenesis inhibition function of CDK $11^{\mathrm{p} 58}$ should be complicated and not only dependent on the VEGF pathway. It needs further investigation.

As $C D K 11^{\mathrm{p} 58}$ is not a transcription factor, we speculated that VEGF promoter activity was indirectly influenced by CDK $11^{\mathrm{p} 58}$. CDK $11^{\mathrm{p} 58}$ might function as a co-repressor or regulate related transcription factors. The exact mechanism requires further investigation. In addition, $\mathrm{CDK} 11^{\mathrm{p} 58}$ inhibited the protein expression of VEGF, CD31, and integrin $\beta 3$. Several reports revealed that some breast cancer cells acquired CD31 expression [36]. CD31 expression mainly correlates with tumor cells spreading within the ductal system [37]. Additionally, CD31 can effluence the growth and differentiation of human breast cancer cells. Despite the expression level is relatively low in the breast cancer cells we investigated, CDK $11^{\mathrm{p} 58}$ further inhibited its expression. Along with VEGF, it could further explain the inhibition effect of growth and angiogenesis by CDK $11^{\mathrm{p} 58}$.

In our previous study, it showed that $\mathrm{CDK} 11^{\mathrm{p} 58}$ could promote the ubiquitin-proteasome degradation of ER alpha [13]. In this study, the data showed that CDK11 ${ }^{\mathrm{p} 58}$ inhibited the tumor growth and angiogenesis both in MDA-MB-231 ER-negative cells and in T47D ERpositive cells. Also, we found CDK11 ${ }^{\mathrm{p} 58}$ inhibited VEGF promoter activity in MDA-MB-231, T47D and $293 \mathrm{~T}$ cells. So we speculated that it was ER independent. CDK $11^{\mathrm{p} 58}$ inhibited the tumor growth and angiogenesis in an ER independent way.

CDK $11^{\mathrm{p} 58}$ is a Ser/Thr kinase and most of its functions are kinase-dependent. Thus, we hypothesized that VEGF inhibition was also CDK11 ${ }^{\mathrm{p} 58}$ kinase dependent. Because we previously showed that Thr370 of CDK11 ${ }^{\mathrm{p} 58}$ was responsible for CDK11 ${ }^{\mathrm{p} 58}$ autophosphorylation, dimerization and kinase activity, mutant T370D and T370A were constructed. In addition, the mutant D224N was reported to be a kinase dead mutant. Indeed, the kinase constantly activated mutant T370D significantly inhibited the VEGF promoter activity compared with the kinase-dead mutant T370A and D224N. The same pattern was obtained at the protein level. These data suggest that the VEGF signaling pathway is inhibited by phosphorylation triggered by CDK11 ${ }^{\mathrm{p} 58}$ and that $\mathrm{CDK} 11^{\mathrm{p} 58}$ inhibits angiogenesis through VEGF signaling in a kinase dependent manner. CDK $11^{\mathrm{p} 58}$ could function through phosphorylating some substrates to be involved in the regulation of VEGF transcription. Base on this result, we will further investigate its mechanism through finding CDK $11^{\mathrm{p} 58}$ substrates by MS analysis. 


\section{Conclusions}

Taken together, our data show that CDK $11^{\mathrm{p} 58}$ inhibits the growth and angiogenesis of breast cancer through inhibiting the regulation of VEGF signaling in a kinase activity dependent manner.

\section{Additional file}

Additional file 1: Figure S1. (A) Colony formation of T47D cells stably transfected with CDK11 ${ }^{\mathrm{p} 58}$ or pCDNA3.0. (B) Tumorigenesis after injection of T47D cells stably expressing CDK $11^{\mathrm{p} 58}$ or control pBABE. Growth curve with $\mathrm{CDK} 11^{\mathrm{p} 58}$ stable expression and controls was also shown below. (C) $\mathrm{CDK} 11^{\mathrm{p} 58}$ inhibits the vascularization of tumors of T47D in mice. Figure S2. (A) Western blot analysis of angiogenesis-related proteins by CDK $11^{\mathrm{p} 58}$. The normalized quantification of immunoblotting data from triplicate experiments were shown as below. (B) Western blot analysis of angiogenesis related proteins by CDK $11^{\mathrm{p} 58}$ and its mutations. The normalized quantification of immunoblotting data from triplicate experiments were shown as below. ${ }^{*} p<0.05 ;{ }^{* *} p<0.001$. (DOC $1612 \mathrm{~kb}$ )

\section{Abbreviations}

CDK11: Cyclin dependent kinase 11; CDC2L1: Cell Division Cycle 2-like 1; ER: Estrogen receptor; VEGF: Vascular endothelial growth factor; IHC: Immunohistochemistry; HUVEC: Human umbilical vein endothelial cells; CD31: Platelet endothelial cell adhesion molecule-1; MMP: Matrix metalloproteinase; ITGB3: integrin $\beta 3$.

\section{Competing interests}

The authors declare that they have no conflicts of interest.

\section{Authors' contributions}

JW and JZ conceived and designed the study. YC and SH performed the experiments. HP analyzed the data. ML and YC contributed reagents, materials and analysis tools. YC wrote the paper. All authors read and approved the final manuscript.

\section{Acknowledgements}

This work was supported by the National Natural Scientific Foundation of China (81102002) and the National Basic Research Program of China (2010CB834305, 2010CB834301).

\section{Author details}

${ }^{1}$ Department of Breast Surgery, Breast Cancer Institute, Fudan University Shanghai Cancer Center, Shanghai 200032, China. ${ }^{2}$ School of Biomedical Engineering, hanghai Jiao Tong University, Shanghai 200240, China.

\section{Received: 5 September 2014 Accepted: 7 October 2015}

Published online: 15 October 2015

\section{References}

1. Carmeliet P, Jain RK. Molecular mechanisms and clinical applications of angiogenesis. Nature. 2011:473(7347):298-307.

2. Fidler IJ. The pathogenesis of cancer metastasis: the 'seed and soil' hypothesis revisited. Nat Rev Cancer. 2003;3(6):453-8.

3. Park MS, Dong SM, Kim BR, Seo SH, Kang S, Lee EJ, et al. Thioridazine inhibits angiogenesis and tumor growth by targeting the VEGFR-2/PI3K/mTOR pathway in ovarian cancer xenografts. Oncotarget. 2014;5(13):4929-34.

4. Hanahan D, Weinberg RA. Hallmarks of cancer: the next generation. Cell. 2011;144(5):646-74.

5. Chen PC, Cheng HC, Wang J, Wang SW, Tai HC, Lin CW, et al. Prostate cancer-derived CCN3 induces M2 macrophage infiltration and contributes to angiogenesis in prostate cancer microenvironment. Oncotarget. 2014;5(6):1595-608.

6. Folkman J, Shing Y. Angiogenesis. J Biol Chem. 1992;267(16):10931-4.

7. Yoshiji H, Gomez DE, Shibuya M, Thorgeirsson UP. Expression of vascular endothelial growth factor, its receptor, and other angiogenic factors in human breast cancer. Cancer Res. 1996;56(9):2013-6.
8. Weidner N, Folkman J, Pozza F, Bevilacqua P, Allred EN, Moore DH, et al. Tumor angiogenesis: a new significant and independent prognostic indicator in early-stage breast carcinoma. J Natl Cancer Inst. 1992;84(24):1875-87

9. Zhang S, Cai M, Zhang S, Xu S, Chen S, Chen X, et al. Interaction of p58 (PITSLRE), a G2/M-specific protein kinase, with cyclin D3. J Biol Chem. 2002;277(38):35314-22.

10. Franck N, Montembault E, Rome P, Pascal A, Cremet JY, Giet R. CDK11 (p58) is required for centriole duplication and PIk4 recruitment to mitotic centrosomes. PLoS ONE. 2011;6(1):e14600.

11. Petretti C, Savoian M, Montembault E, Glover DM, Prigent C, Giet R. The PITSLRE/CDK11p58 protein kinase promotes centrosome maturation and bipolar spindle formation. Embo Rep. 2006;7(4):418-24.

12. Zong H, Chi Y, Wang $Y$, Yang $Y$, Zhang L, Chen H, et al. Cyclin D3/ CDK11p58 complex is involved in the repression of androgen receptor. Mol Cell Biol. 2007;27(20):7125-42.

13. Wang $Y$, Zong $H$, Chi $Y$, Hong $Y$, Yang $Y$, Zou W, et al. Repression of estrogen receptor alpha by CDK11p58 through promoting its ubiquitinproteasome degradation. J Biochem. 2009;145(3):331-43.

14. Chi $Y$, Wang $L$, Xiao $X$, Wei $P$, Wang $Y$, Zhou X. Abnormal expression of CDK11p58 in prostate cancer. Cancer Cell Int. 2014;14(1):2.

15. Chi $Y$, Huang $S$, Wang $L$, Zhou R, Wang L, Xiao X, et al. CDK11p58 inhibits ERalpha-positive breast cancer invasion by targeting integrin beta3 via the repression of ERalpha signaling. BMC Cancer. 2014;14:577.

16. Terzuoli E, Meini S, Cucchi P, Catalani C, Cialdai C, Maggi CA, et al. Antagonism of bradykinin $\mathrm{B} 2$ receptor prevents inflammatory responses in human endothelial cells by quenching the NF-kB pathway activation. PLoS ONE. 2014;9(1):e84358.

17. Jin W, Chen BB, Li JY, Zhu H, Huang M, Gu SM, et al. TIEG1 inhibits breast cancer invasion and metastasis by inhibition of epidermal growth factor receptor (EGFR) transcription and the EGFR signaling pathway. Mol Cell Biol. 2012;32(1):50-63.

18. Chi Y, Zhang C, Zong H, Hong Y, Kong X, Liu H, et al. Thr-370 is responsible for CDK11 (p58) autophosphorylation, dimerization, and kinase activity. J Biol Chem. 2011;286(3):1748-57.

19. Lam HM, Suresh BC, Wang J, Yuan Y, Lam YW, Ho SM, et al. Phosphorylation of human estrogen receptor-beta at serine 105 inhibits breast cancer cell migration and invasion. Mol Cell Endocrinol. 2012;358(1):27-35.

20. Keyhani E, Muhammadnejad A, Behjati F, Sirati F, Khodadadi F, Karimlou M, et al. Angiogenesis markers in breast cancer-potentially useful tools for priority setting of anti-angiogenic agents. Asian Pac J Cancer Prev. 2013:14(12):7651-6

21. Shim HJ, Kim SH, Kang BJ, Choi BG, Kim HS, Cha ES, et al. Breast cancer recurrence according to molecular subtype. Asian Pac J Cancer Prev. 2014;15(14):5539-44.

22. Ahmad A, Sethi S, Chen W, Ali-Fehmi R, Mittal S, Sarkar FH. Up-regulation of microRNA-10b is associated with the development of breast cancer brain metastasis. Am J Transl Res. 2014;6(4):384-90.

23. Subramonian D, Raghunayakula S, Olsen JV, Beningo KA, Paschen W, Zhang XD. Analysis of Changes in SUMO-2/3 Modification during Breast Cancer Progression and Metastasis. J Proteome Res. 2014;13(9):3905-18.

24. Mokhtar M, Tadokoro Y, Nakagawa M, Morimoto M, Takechi H, Kondo K, Tangoku A: Triple assessment of sentinel lymph node metastasis in early breast cancer using preoperative CTLG, intraoperative fluorescence navigation and OSNA. Breast Cancer 2014, Jul 29. [Epub ahead of print].

25. Dimova I, Popivanov G, Djonov V. Angiogenesis in cancer - general pathways and their therapeutic implications. J BUON. 2014;19(1):15-21.

26. Chakraborty S, Adhikary A, Mazumdar M, Mukherjee S, Bhattacharjee P, Guha D, et al. Capsaicin-Induced Activation of p53-SMAR1 Auto-Regulatory Loop Down-Regulates VEGF in Non-Small Cell Lung Cancer to Restrain Angiogenesis. PLOS ONE. 2014;9(6):e99743.

27. Chen S, Yin X, Zhu X, Yan J, Ji S, Chen C, et al. The C-terminal kinase domain of the p34cdc2-related PITSLRE protein kinase (p110C) associates with p21-activated kinase 1 and inhibits its activity during anoikis. J Biol Chem. 2003;278(22):20029-36.

28. Yokoyama H, Gruss OJ, Rybina S, Caudron M, Schelder M, Wilm M, et al. Cdk11 is a RanGTP-dependent microtubule stabilization factor that regulates spindle assembly rate. J Cell Biol. 2008;180(5):867-75.

29. Hu D, Valentine M, Kidd VJ, Lahti JM. CDK11 (p58) is required for the maintenance of sister chromatid cohesion. J Cell Sci. 2007;120(Pt 14):2424-34 
30. Yun $X$, Wu Y, Yao L, Zong H, Hong Y, Jiang J, et al. CDK11 (p58) protein kinase activity is associated with $\mathrm{BCl}-2$ down-regulation in pro-apoptosis pathway. Mol Cell Biochem. 2007;304(1-2):213-8.

31. Wilkinson S, Croft DR, O'Prey J, Meedendorp A, O'Prey M, Dufes C, et al. The cyclin-dependent kinase PITSLRE/CDK11 is required for successful autophagy. Autophagy. 2011;7(11):1295-301.

32. Kong X, Gan H, Hao Y, Cheng C, Jiang J, Hong Y, et al. CDK11p58 phosphorylation of PAK1 Ser174 promotes DLC2 binding and roles on cell cycle progression. J Biochem. 2009;146(3):417-27.

33. Zhang $X, X u W H, G e Y L$, Hou L, Li Q. Effect of siRNA transfection targeting VEGF gene on proliferation and apoptosis of human breast cancer cells. Xi Bao Yu Fen Zi Mian Yi Xue Za Zhi. 2007;23(1):14-7.

34. Ge YL, Zhang X, Zhang JY, Hou L, Tian RH. The mechanisms on apoptosis by inhibiting VEGF expression in human breast cancer cells. Int Immunopharmacol. 2009;9(4):389-95.

35. Zhang Q, Gan H, Cheng Z, Zhao S, Chen C, Jiang C, et al. 2-Deoxy-Dglucose combined with Taxol inhibits VEGF expression and induces apoptosis in orthotopically transplanted breast cancer in $\mathrm{C} 3 \mathrm{H}$ mice. Nan Fang Yi Ke Da Xue Xue Bao. 2014;34(2):193-6.

36. Sapino A, Bongiovanni M, Cassoni P, Righi L, Arisio R, Deaglio S, et al. Expression of CD31 by cells of extensive ductal in situ and invasive carcinomas of the breast. J Pathol. 2001;194(2):254-61.

37. Righi L, Deaglio S, Pecchioni C, Gregorini A, Horenstein AL, Bussolati G, et al. Role of CD31/platelet endothelial cell adhesion molecule-1 expression in in vitro and in vivo growth and differentiation of human breast cancer cells. Am J Pathol. 2003;162(4):1163-74.

\section{Submit your next manuscript to BioMed Central and take full advantage of:}

- Convenient online submission

- Thorough peer review

- No space constraints or color figure charges

- Immediate publication on acceptance

- Inclusion in PubMed, CAS, Scopus and Google Scholar

- Research which is freely available for redistribution 